\title{
The Effect of Thermal Inputs on Microstructure and Corrosion Resistance of WC Particle-Reinforced High Chromium Wear- Resistant Steel
}

\author{
Ben Niu ${ }^{1}$, Junfu Chen ${ }^{1, *}$, Yaoyong $\mathrm{Yi}^{1}$, Linlin Pan ${ }^{1}$, Xiaodong Zou ${ }^{1}$, Jianglong $\mathrm{Yi}^{1}$, Yongjun Hu ${ }^{2}$ \\ ${ }^{1}$ Guangdong Provincial Key Laboratory of Advanced Welding Technology, China-Ukraine Institute of \\ Welding, Guangdong Academy of Sciences (China-Ukraine E. O. Paton Institute of Welding), \\ Guangzhou, Guangdong, 510650, P.R. China; \\ ${ }^{2}$ Guangdong University of Technology, Guangzhou 510006, P.R. China. \\ *E-mail: niub@gwi.gd.cn
}

Received: 18 December 2020 / Accepted: 2 March 2021 / Published: 31 May 2021

\begin{abstract}
The purpose of this study is to improve corrosion resistance of WC particle reinforced high-chromium wear-resistant steel by different thermal inputs. The polarization curve and electrochemical impedance spectroscopy of the sample at a low potential in $3.5 \% \mathrm{NaCl}$ solution were studied by using an electrochemical workstation. Electrochemical changes in the region near the fusion line were examined by scanning vibrating electrode technique (SVET). Micro morphology was explored via an optical microscope (OM). The electrochemical results show that corrosion resistance initially increases and then decreases with increasing thermal inputs. Sample \#2 displayed the highest corrosion potential (-0.491 $\mathrm{V})$ and the lowest corrosion current density $\left(3.78 \times 10^{-4} \mu \mathrm{A} \cdot \mathrm{cm}^{2}\right)$ of all the conditions. The SVET results and microstructure imply that the excellent electrochemical performance of high-chromium wearresistant steel is attributed to the reasonably well thermal inputs, which can both provide efficient elemental distribution and promote the dissolution of the WC phase. This work provides new insight into the improvement of corrosion resistance of high-chromium wear-resistant steel.
\end{abstract}

Keywords: Welding coating, Thermal inputs, microstructure, Electrochemical performance

\section{FULL TEXT}

(C) 2021 The Authors. Published by ESG (www.electrochemsci.org). This article is an open access article distributed under the terms and conditions of the Creative Commons Attribution license (http://creativecommons.org/licenses/by/4.0/). 